\title{
Synergistic effect and condition of pegylated interferon $\alpha$ with paclitaxel on glioblastoma
}

\author{
MYUNG JIN SON ${ }^{1 *}$, HYUN SEOK SONG ${ }^{1 *}$, MI HYUN KIM ${ }^{1}$, JI TAE KIM ${ }^{1,2}$, \\ CHANG-MO KANG $^{2}$, JI WON JEON ${ }^{1,3}$, SHI-YOUNG PARK ${ }^{3}$, YUNG-JIN KIM ${ }^{3}$, \\ MORRIS D. GROVES ${ }^{4}$, KWAN PARK ${ }^{1}$, JONG-HYUN KIM ${ }^{1}$ and DO-HYUN NAM ${ }^{1}$ \\ ${ }^{1}$ Department of Neurosurgery, Samsung Medical Center and Samsung Biomedical Research Institute, \\ Sungkyunkwan University School of Medicine, Seoul 135-710; ${ }^{2}$ Laboratory of Radiation \\ Cytogenetics and Epidemiology, Korea Institute of Radiological and Medical Sciences, Seoul 139-706; \\ ${ }^{3}$ Department of Molecular Biology, Pusan National University, Busan 609-735, Korea; ${ }^{4}$ Department of \\ Neuro-Oncology, The University of Texas M.D. Anderson Cancer Center, Houston, TX 77030, USA
}

Received December 5, 2005; Accepted January 26, 2006

\begin{abstract}
Glioblastomas are highly vascularized tumors and anti-angiogenic strategy is one of the most promising therapeutic approaches to treat brain tumors. Interferon $\alpha$ (IFN- $\alpha$ ) as a single agent or combined with standard chemotherapy has been shown to inhibit various tumors, but the effect of combination anti-angiogenic therapy on brain tumors has not been well studied. We determined the optimal dose and schedule of pegylated IFN- $\alpha$ (PEG-IFN- $\alpha$ ) against U87MG human glioblastoma cells growing orthotopically in nude mice, since several clinical trials reported that PEGIFN- $\alpha$ administered at higher or lower doses was less effective. The group treated two times per week with injections of $10 \mathrm{KU}$ of PEG-IFN- $\alpha$ for 4 weeks showed significant decreases in cell proliferation and angiogenesis. Moreover, the optimal dose and schedule of PEG-IFN- $\alpha$ determined in this study and combined with paclitaxel treatment potently inhibited tumor growth in vivo. The mechanisms of the significant therapeutic effects were most likely caused by directly inhibiting cell proliferation and angiogenesis, and rendering apoptosis increased. Specifically PEG-IFN- $\alpha$ /paclitaxel combination induced apoptosis of tumor-associated endothelial cells more than that of tumor cells. These results suggest that optimal biological dosage and scheduling of PEG-IFN- $\alpha$ and paclitaxel combination is a
\end{abstract}

Correspondence to: Dr Do-Hyun Nam, Department of Neurosurgery, Samsung Medical Center and Samsung Biomedical Research Institute, Sungkyunkwan University School of Medicine, 50 Ilwon-Dong, Kangnam-Ku, Seoul 135-710, Korea

E-mail:nsnam@smc.samsung.co.kr

${ }^{*}$ Contributed equally

Key words: glioblastoma, PEG-IFN- $\alpha$, paclitaxel, anti-endothelial treatment potent strategy for glioblastoma patients as a new synergistic anti-endothelial treatment.

\section{Introduction}

Glioblastoma is the most common type of primary malignant brain tumor (1). Following surgical resection or biopsy, adjuvant radiation and chemotherapy are moderately effective in prolonging time to recurrence and survival, yet aggressive conventional therapies are only modestly effective at the time of recurrence (2). Therefore, the search for new agents and innovative approaches for this disease became important.

IFNs are a family of natural glycoproteins with antiviral activity (3). Studies have revealed that IFNs are multifunctional through a combination of direct activities and indirect immune-mediated effects (4). IFNs also regulate cell proliferation, differentiation, and development (5-7) and directly inhibit the proliferation of tumor cells of various histological origins (8-10).

IFN- $\alpha$ down-regulates the expression of the proangiogenic molecules, such as basic fibroblast growth factor (bFGF) $(11,12)$, IL-8 (13), and matrix metalloproteinase (MMP)-2 and $-9(14,15)$ and inhibits the motility of vascular endothelial cells in vitro (16) and angiogenesis in vivo $(17,18)$. Gliomas are highly vascularized tumors (19) with extremely elevated levels of numerous proangiogenic factors (20-22). Inhibiting the sprouting of new capillaries from preexisting blood vessels is one of the most promising therapeutic approaches for gliomas. In addition, IFN- $\alpha$ combined with other anti-angiogenic drugs has been shown to inhibit tumor growth in ovarian carcinoma (23) but the effects of combination anti-angiogenic therapy on brain tumors has not been well studied.

Several clinical trials have investigated the use of natural and recombinant IFN- $\alpha$ as a single agent or combined with standard chemotherapy and showed various responses. In analyzing the results of treatment programs for cancer, optimization of biological dose and scheduling of IFN- $\alpha$ are important $(24,25)$. We used PEG-IFN- $\alpha$ in this study; it is a 


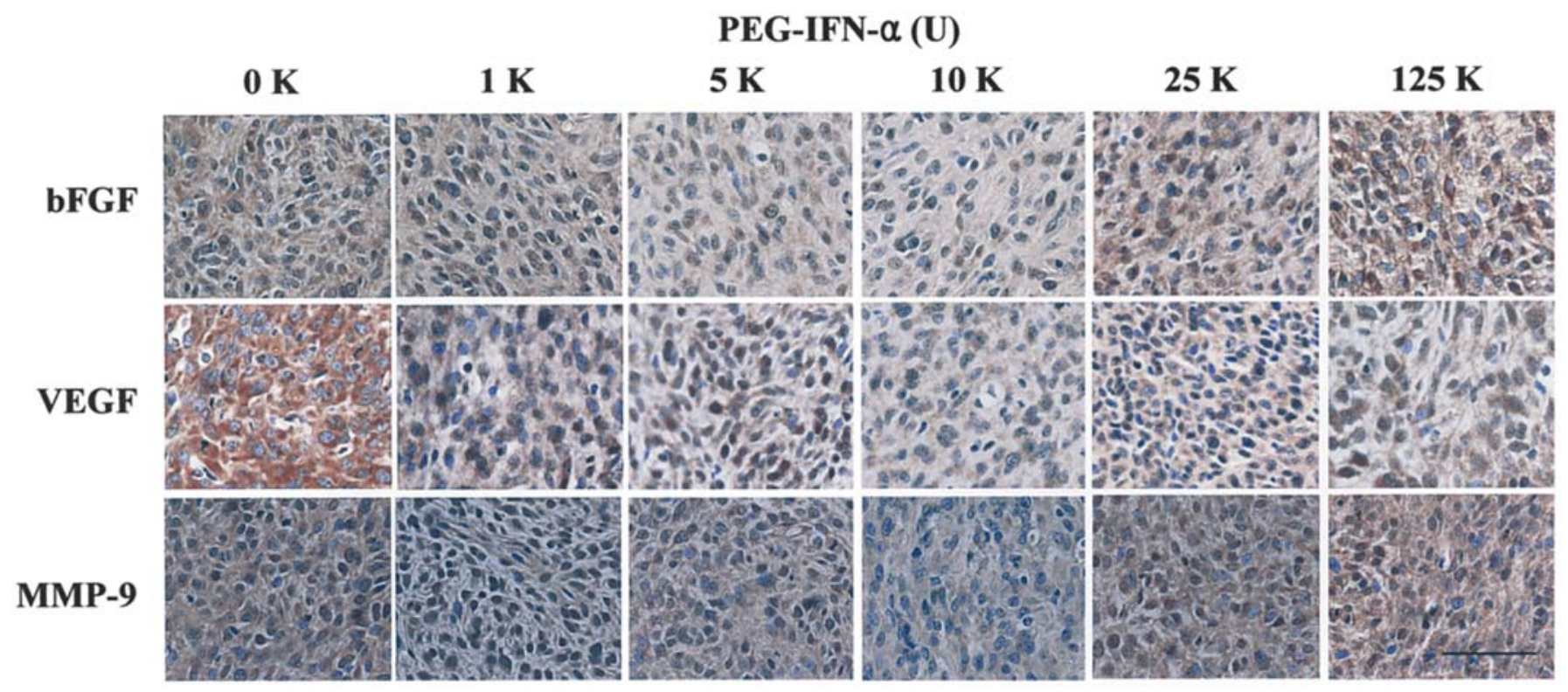

Figure 1. Determination of the optimal biological dose of PEG-IFN- $\alpha$ in glioma xenografts. U-87MG glioblastoma cells were orthotopically implanted into mouse brains and then $1,5,10,25$, or $125 \mathrm{KU}$ of PEG-IFN- $\alpha$ was administered s.c. three times, on the 19th, 23rd, and 26th day after tumor cell inoculation. The mice were sacrificed on day 28 and the brain samples were immunostained with anti-bFGF, anti-VEGF or anti-MMP-9 antibodies, respectively. Scale bar, $100 \mu \mathrm{m}$.

potent, long-lasting form of IFN- $\alpha$ designed to enhance its pharmacokinetic characteristics and reduce immunogenicity. A phase I study has demonstrated the potential efficacy of PEG-IFN- $\alpha$ in renal cell carcinoma (26). However, PEG-IFN- $\alpha$ administered at higher or lower doses was less effective; repetitive daily dosing trials have shown some accumulation of toxicity, although experience is still greater with the daily schedule of administration (25). Therefore, to produce maximal therapeutic effects, PEG-IFN- $\alpha$ must be administered at an optimal biological dose and schedule. The purpose of the present study is to reveal the synergistic effect of PEGIFN- $\alpha$ /paclitaxel by analysis and determine the optimal biological dose and schedule of PEG-IFN- $\alpha$ alone and in combination with paclitaxel in a reliable, preclinical, in vivo model of human glioblastoma cells orthotopically growing in nude mice.

\section{Materials and methods}

Cell culture. U-87MG human glioblastoma cells (ATCC) were grown in Eagle's minimal essential medium (Cambrex) supplemented with $10 \%$ fetal bovine serum and antibiotics (Life Technologies).

Animals and orthotopic implantation of tumor cells. Specific pathogen-free male balb/c-nu mice were used. All animal work was approved by the Association for Assessment and Accreditation of Laboratory Animal Care International and in accordance with current regulations and standards of Laboratory Animal Research Center under Samsung Biomedical Research Institute. Orthotopic implantation of glioma cells was performed as described previously (27). Briefly, balb/c-nu mice (6 weeks) were anesthetized with an intraperitoneal injection of $100 \mathrm{mg} / \mathrm{kg}$ ketamin and $10 \mathrm{mg} / \mathrm{kg}$ xylazine. The heads of the anesthetized mice were shaved and disinfected with a solution of $70 \%$ ethyl alcohol and povidone iodine. They were secured in a rodent stereotactic frame, and a hollow guide screw was implanted into a small drill hole made $2 \mathrm{~mm}$ left lateral and $1 \mathrm{~mm}$ anterior to the bregma (28). U-87MG tumor cells ( $2 \times 10^{5}$ cells $/ 5 \mu 1$ of HBSS) were injected through this guide screw into the white matter at a depth of $2 \mathrm{~mm}$ through a $10-\mu 1$ Hamilton syringe connected to the manipulating arm of the produced 7-stereotatic device.

Drug administration. PEG-IFN- $\alpha$ (pegylated IFN- $\alpha-2 b)$ and Taxol (Paclitaxel) were obtained from Schering-Plough and Bristol-Myers Squibb Pharmaceuticals, respectively, and both were dissolved in PBS. To determine the optimal biological dose of PEG-IFN- $\alpha$, tumor cells were orthotopically implanted and the mice were randomized into six groups ( $n=5$ per group). PBS (control group) or 1, 5, 10, 25, and $125 \mathrm{KU}$ of PEGIFN- $\alpha$ was administered subcutaneously (s.c.) three times (on the 19th, 23rd, and 26th day after tumor cell inoculation). The mice were sacrificed on day 28, and the brain samples were used for immunohistochemistry for bFGF, vascular endothelial growth factor (VEGF), and MMP-9. To determine the effective treatment schedule of $10 \mathrm{KU}$ of PEG-IFN- $\alpha$, during 4 weeks after implantation of tumor cells, one group of mice $(n=6)$ were treated with $10 \mathrm{KU}$ of PEG-IFN- $\alpha$ two times per week for the entire 4 weeks and the other group $(n=6)$ were treated for the last 2 weeks of the 4 week period. In the next set of combination treatment studies, the mice were randomized into four groups $(n=6)$ : PBS (control group), $10 \mathrm{KU}$ of PEG-IFN- $\alpha, 200 \mu \mathrm{g}$ of paclitaxel, or PEG-IFN- $\alpha /$ paclitaxel combination. PEG-IFN- $\alpha$ and paclitaxel was administered two times per week for 4 weeks s.c. and intraperitoneally (i.p.), respectively.

Harvesting of specimens. The mice were sacrificed and their brains were removed and sectioned axially. One section was 
fixed in $10 \%$ buffered formalin and embedded in paraffin, and the other was embedded in OCT compound (Miles, Inc.), frozen rapidly in liquid nitrogen, and stored at $-70^{\circ} \mathrm{C}$. The tumor volume was calculated by measuring the section with the largest tumor portion and applying the formula: width ${ }^{2} \mathrm{x}$ length $\mathrm{x} 0.5$.

Immunohistochemistry. Immunohistochemistry was performed as described previously (27). The following antibodies were used to stain their respective antigens: rabbit anti-bFGF (Sigma Chemical Co.), rabbit anti-VEGF (Santa Cruz Biotechnology), rabbit anti-MMP9 (Chemicon), rat anti-mouse CD31/PECAM1 (BD Pharmingen), mouse anti-PCNA clone PC 10 (Dako), peroxidase-conjugated anti-rat IgG (Jackson Immunoresearch), peroxidase-conjugated anti-rabbit IgG and biotinylated anti-mouse $\mathrm{IgG}$ (Vector), and biotinylated goat anti-rabbit IgG (Zymed). The DeadEnd fluorometric TUNEL system (Promega) was used to assay apoptosis. The other reagents were stable 3,3'-diaminobenzidine (Research Genetics), Gills hematoxylin (Polysciences), an ABC kit (Vector), and Target retrieval solution and Dako pen (Dako).

Quantification of immunostaining. To quantify the immunohistochemical reaction intensities for bFGF, VEGF, and MMP, the cytoplasmic immunoreactivity (absorbance) was evaluated in five fields representing areas of highest staining intensity. Each field was evaluated by computer-assisted image analysis using Optimas software program (Bioscan; 29,30). For the quantification of immunostaining for PCNA and TUNEL assay, the number of stained cells was counted in ten random fields at magnification $\mathrm{x} 400$. For CD31, the number of stained cells was counted in ten random fields at a magnification of $\mathrm{x} 200$.

Data analysis and statistics. Values are presented as means \pm $\mathrm{SE}$ or \pm SD. Statistical comparisons between groups were performed using Student's t-test, or Mann-Whitney test with Bonferroni's correction. Values of $\mathrm{P}<0.05$ were considered statistically significant.

\section{Results}

Determination of the optimal biological dose of PEG-IFN- $\alpha$. To evaluate the most therapeutically efficacious dose of PEG-IFN- $\alpha$, we examined the expression of angiogenic activators by PEG-IFN- $\alpha$ in human glioblastoma cells orthotopically growing in nude mice. Considering that gliomas are hypervascularized brain tumors and are dependant on angiogenesis for their growth, we examined the anti-angiogenic potential of PEG-IFN- $\alpha$ using immunohistological staining of the major angiogenic activators, bFGF, VEGF and MMP-9 (Fig. 1). U-87MG human glioblastoma cells were orthotopically implanted into mouse brains and then 1, 5, 10, 25, or $125 \mathrm{KU}$ of PEG-IFN- $\alpha$ was administered s.c. three times, on the 19th, 23rd, and 26th day after tumor cell inoculation. Basic-FGF, VEGF and MMP-9 were strongly expressed in control tumors $(0 \mathrm{KU})$. The expression of each was significantly decreased by treatment of $10 \mathrm{KU}$ of PEG-IFN- $\alpha$, while 25 or $125 \mathrm{KU}$ of PEG-IFN- $\alpha$ showed robust expression similar to that of controls. Treatment with $10 \mathrm{KU}$ of PEG-IFN- $\alpha$ led
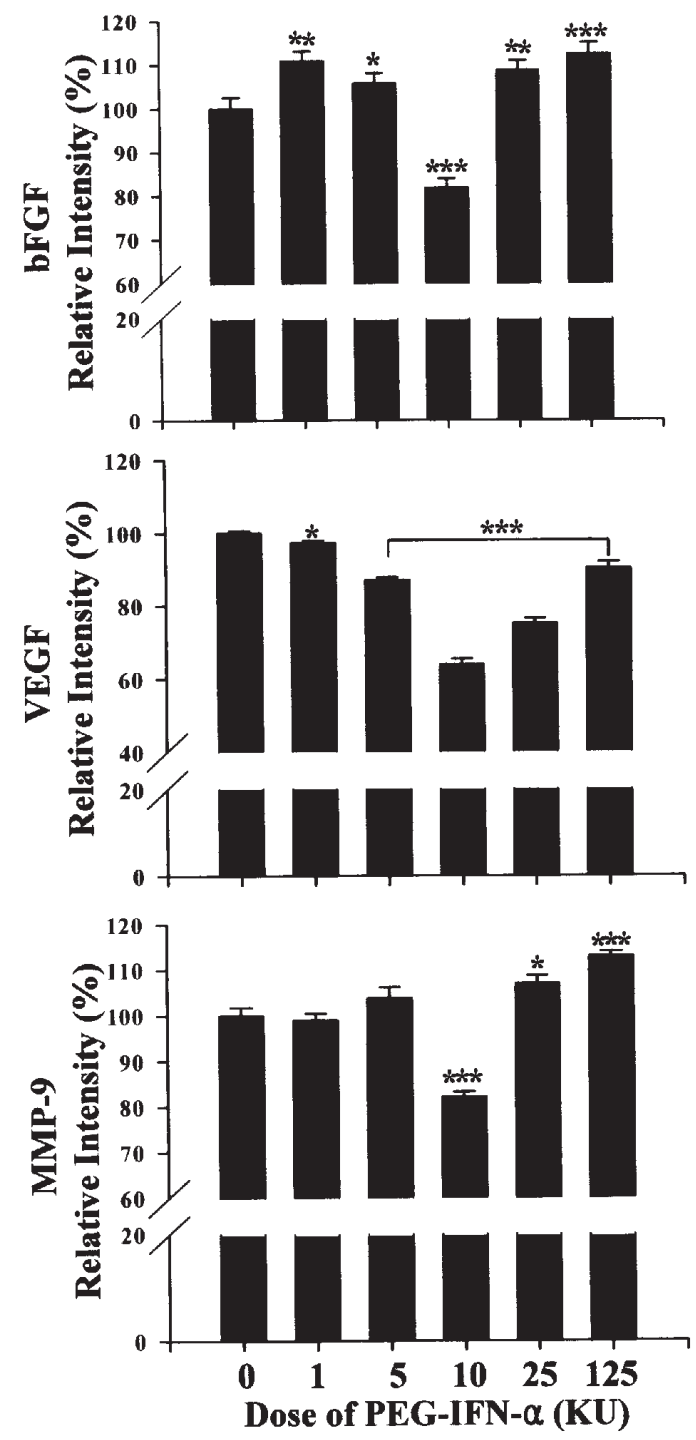

Figure 2. Quantification of immunohistochemical analysis for bFGF, VEGF and MMP-9. Absorbance of stained cells was measured, and the intensity of immunohistochemical reaction relative to the controls are represented (\%). ${ }^{*} \mathrm{P}<0.05,{ }^{* *} \mathrm{P}<0.01$, and ${ }^{* * * *} \mathrm{P}<0.001$ compared to the controls $(0 \mathrm{KU}$ of PEGIFN- $\alpha$ ).

to an $18 \%(\mathrm{P}<0.0001), 36 \%(\mathrm{P}<0.0001)$, or $18 \%(\mathrm{P}<0.0001)$ decrease in the intensity of bFGF, VEGF and MMP-9 immunostaining in tumor tissue relative to the controls, respectively (Fig. 2).

Determination of the optimal biological schedule of PEG$I F N-\alpha$. To determine the effective treatment schedule of $10 \mathrm{KU}$ of PEG-IFN- $\alpha$, after implantation of tumor cells, PEG-IFN- $\alpha$ at $10 \mathrm{KU}$ was administered two times per week either for the entire 4 weeks or for the last 2 weeks of the 4-week treatment period. Compared to untreated control animals, PEG-IFN- $\alpha$ at $10 \mathrm{KU}$ significantly decreased tumor uptake by $50 \%$ or $60 \%$ in 2 weeks versus 4 weeks treatment regimen, respectively. There were no signs of toxicity of drug administration, such as body weight loss (data not shown). The group treated with $10 \mathrm{KU}$ of PEG-IFN- $\alpha$ for 4 weeks showed significant decrease of cell proliferation as compared with the group treated with PEG-IFN- $\alpha$ for 2 weeks (Fig. 3). The number of proliferating 
A

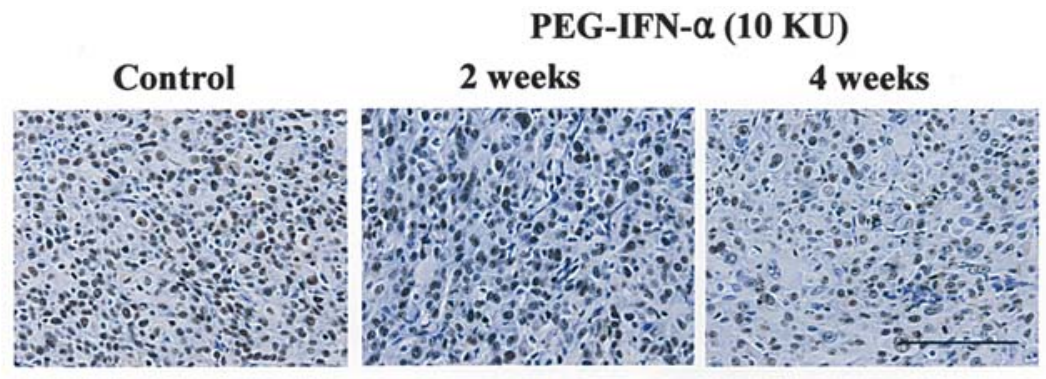

B

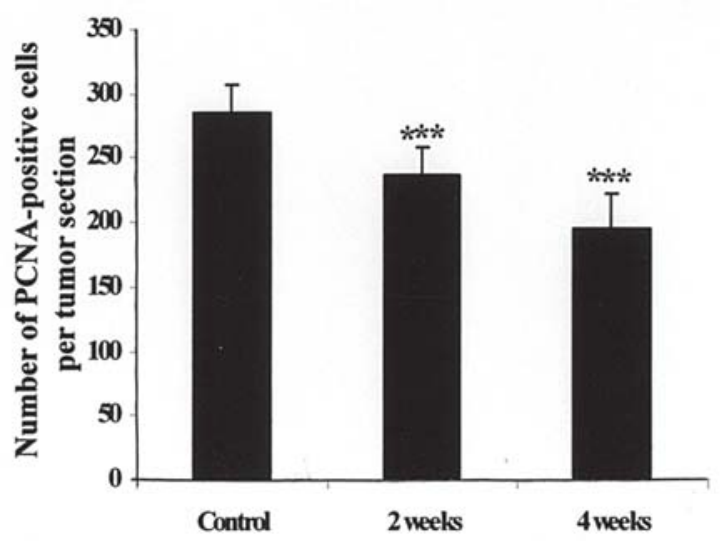

Figure 3. Inhibition of cell proliferation by treatment schedule of PEG-IFN- $\alpha$ in glioma xenografts. Tumor cells were orthotopically implanted into mouse brains and then PEG-IFN- $\alpha$ at $10 \mathrm{KU}$ was administered two times per week for the entire 4 weeks or for the last 2 weeks of the 4 week period. A, paraffin sections of tumors were stained for proliferating cells using an anti-PCNA antibody. Scale bar, $100 \mu \mathrm{m}$. B, mean number of PCNA-positive cells is shown $(\mathrm{n}=10) .{ }^{* * *} \mathrm{P}<0.001$ compared to the controls.

A

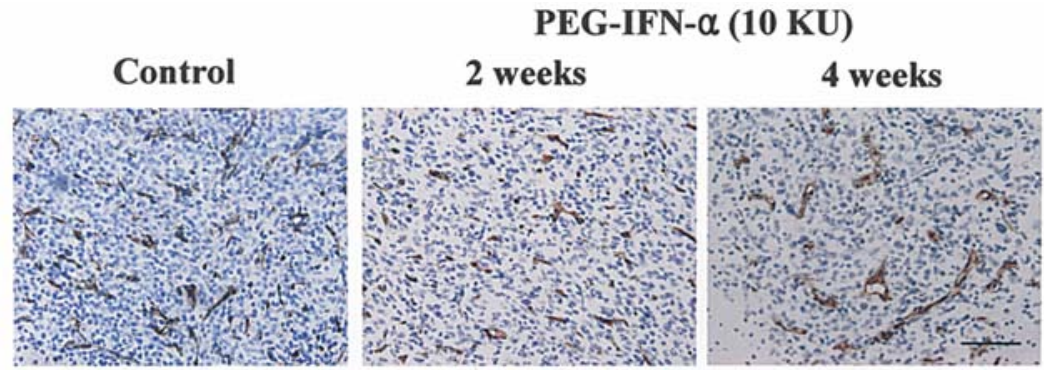

B

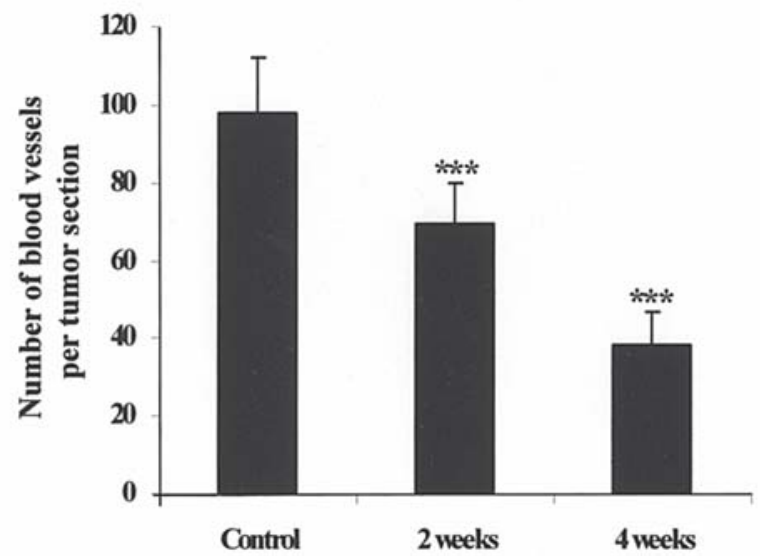

Figure 4. Inhibition of microvessel density by treatment schedule of PEG-IFN- $\alpha$ in glioma xenografts. A, frozen sections of tumors were stained for endothelial cells with anti-CD31 antibody. Scale bar, $100 \mu \mathrm{m}$. B, mean number of blood vessels is shown $(\mathrm{n}=9) .{ }^{* * *} \mathrm{P}<0.001$ compared to the controls. 


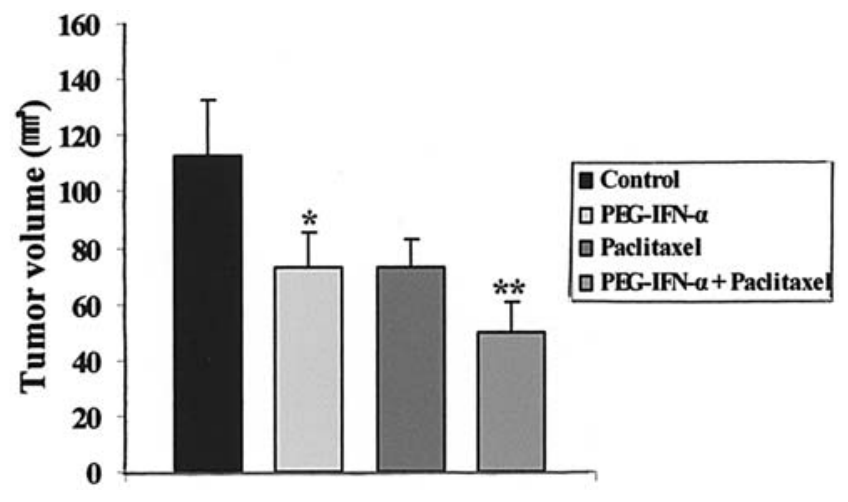

Figure 5. Synergistic inhibition of tumor growth by optimal dose and schedule of PEG-IFN- $\alpha$ /paclitaxel combination in glioma xenografts. Tumor cells were orthotopically implanted into mouse brains and then the mice received PBS (control), $10 \mathrm{KU}$ of PEG-IFN- $\alpha, 200 \mu \mathrm{g}$ of paclitaxel, or PEGIFN- $\alpha$ /paclitaxel combination. PEG-IFN- $\alpha$ and paclitaxel was administered two times per week for 4 weeks s.c. and i.p., respectively. Tumor volumes are shown as the mean \pm SE from 6 mice. ${ }^{*} \mathrm{P}<0.05$ and ${ }^{* *} \mathrm{P}<0.01$ compared to the controls.

cells stained with PCNA was decreased by $17 \%(\mathrm{P}=0.0003)$ and $32 \%(\mathrm{P}<0.0001)$ in 2 weeks and 4 weeks, respectively, in treated mice as compared with control mice. Next, we examined the decrease of tumor vascularization depending on the schedule of PEG-IFN- $\alpha$ using immunohistological staining of CD31 (Fig. 4). The number of CD31-stained vessels was decreased by $29 \%(\mathrm{P}=0.0002)$ and $61 \%(\mathrm{P}<0.0001)$ in the 2-week and 4-week treated groups of mice as compared with the controls, respectively. These results demonstrate that treatment with $10 \mathrm{KU}$ of PEG-IFN- $\alpha$ for 4 weeks reduced the tumor uptake, proliferation, and angiogenesis, suggesting an effective dose and schedule for PEG-IFN- $\alpha$.

Synergistic therapy of PEG-IFN- $\alpha$ and paclitaxel. We determined whether administration of the optimal biological dose and schedule of PEG-IFN- $\alpha$ combined with paclitaxel would produce additive or synergistic therapeutic effects. Tumor cells were orthotopically implanted into mouse brains and then the mice received PBS (control), 10 KU of PEGIFN- $\alpha, 200 \mu \mathrm{g}$ of paclitaxel, or PEG-IFN- $\alpha /$ paclitaxel combination. PEG-IFN- $\alpha$ plus paclitaxel was administered two times per week for 4 weeks s.c. and i.p., respectively. The average tumor volume in PEG-IFN- $\alpha$ - or paclitaxel-treated mice was $35 \%(\mathrm{P}=0.04)$ or $36 \%$ smaller than that in control mice (Fig. 5). The volume was significantly reduced by $56 \%$ in PEG-IFN- $\alpha$ /paclitaxel combination $(\mathrm{P}=0.006)$. These results demonstrate that PEG-IFN- $\alpha$ /paclitaxel combination was more effective in tumor growth inhibition than either PEGIFN- $\alpha$ or paclitaxel alone.

As PEG-IFN- $\alpha$ /paclitaxel combination inhibited tumor mass, we examined cell proliferation, apoptosis and vessel density by immunostaining for PCNA, by TUNEL assay, and by immunostaining for CD31, respectively (Fig. 6). The number of strongly stained PCNA-positive cells seen in the control tumors was decreased in both PEG-IFN- $\alpha$ - and paclitaxel-treated mice, by $34 \%(\mathrm{P}<0.0001)$ and by $19 \%$ $(\mathrm{P}=0.001)$ relative to the controls, respectively. PEG-IFN- $\alpha /$ paclitaxel combination dramatically reduced the number of PCNA-positive cells by $62 \%(\mathrm{P}<0.0001)$ (Fig. 7). The number of apoptotic cells stained in the TUNEL assay was increased by treatment with either PEG-IFN- $\alpha$ (5.2-fold increase,

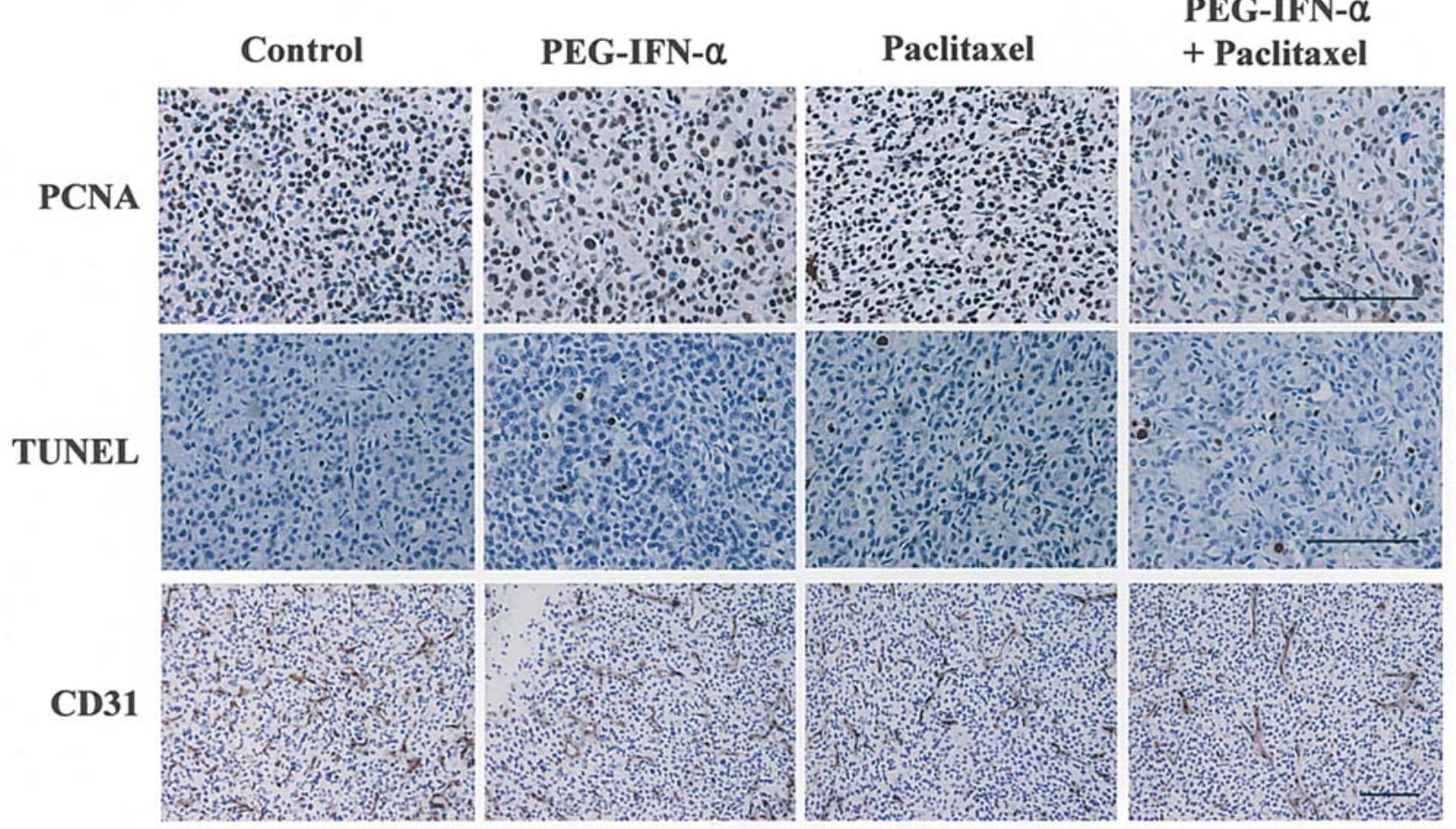

Figure 6. Effects of PEG-IFN- $\alpha$ /paclitaxel combination on the cell proliferation (PCNA), apoptosis (TUNEL), and microvessel density (CD31) in glioma xenografts. Tumor sections were stained for proliferating cells using an anti-PCNA antibody, for apoptotic cells using TUNEL assay, and for endothelial cells with anti-CD31 antibody. Scale bar, $100 \mu \mathrm{m}$. 


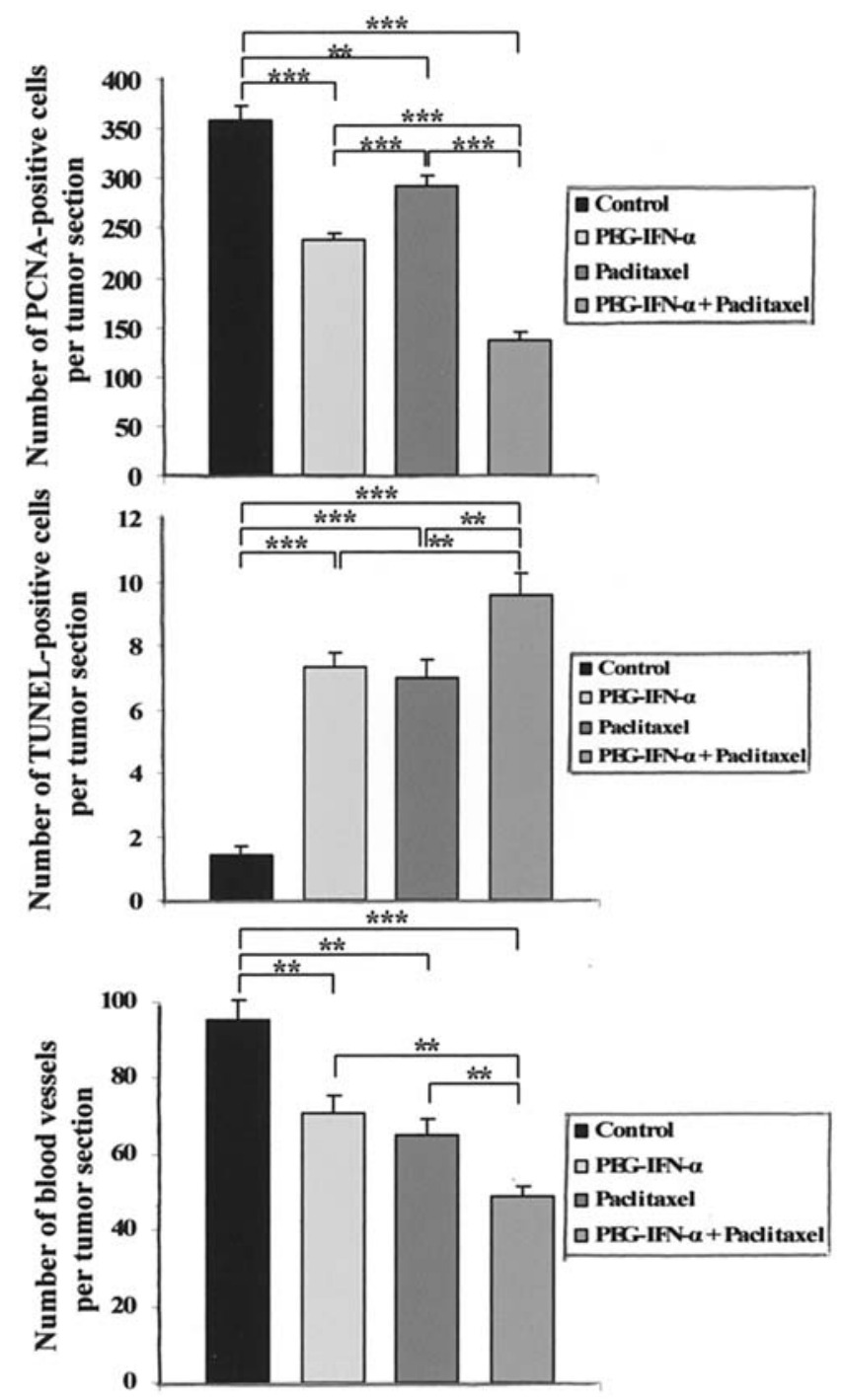

Figure 7. Quantification of immunohistochemical analysis for PCNA, TUNEL, and CD31. Mean numbers of PCNA-positive cells, TUNEL-positive cells, and blood vessels are shown $(\mathrm{n}=10)$. ${ }^{* *} \mathrm{P}<0.01$ and ${ }^{* * *} \mathrm{P}<0.001$.

Table I. Combination treatment with PEG-IFN- $\alpha$ and paclitaxel induced apoptosis of tumor-associated endothelial cells.

A,

Treatment group ${ }^{\mathrm{a}}$

\section{Control}

PEG-IFN- $\alpha$

Paclitaxel

PEG-IFN- $\alpha+$ paclitaxel
$\mathrm{P}<0.0001)$ or paclitaxel (4.9-fold, $\mathrm{P}<0.0001)$ compared with the controls. PEG-IFN- $\alpha /$ paclitaxel combination enhanced the number of apoptotic cells 6.8-fold compared with the controls $(\mathrm{P}<0.0001)$. The number of CD31-stained vessels was reduced in either PEG-IFN- $\alpha$ - or paclitaxel-treated mice, by $26 \%(\mathrm{P}=0.003)$ and by $32 \%(\mathrm{P}=0.002)$ relative to the controls, respectively. PEG-IFN- $\alpha /$ paclitaxel combination dramatically decreased the number of vessels by $48 \%$ $(\mathrm{P}<0.0001)$. Synergistic effects between PEG-IFN- $\alpha$ and paclitaxel were observed in proliferation $(\mathrm{P}=0.002)$, apoptosis $(\mathrm{P}=0.006)$, and vessel density $(\mathrm{P}=0.006)$. These immunohistochemical data demonstrate that the inhibition of tumor growth observed in mice treated with 4 weeks of $10 \mathrm{KU}$ of PEG-IFN- $\alpha$ plus paclitaxel was accompanied by a significant reduction of cell proliferation and tumor vascularization, and increase in apoptosis.

To determine the mechanism of PEG-IFN- $\alpha /$ paclitaxel combination, we examined whether tumor-associated endothelial cells underwent apoptosis using the CD31/TUNEL fluorescent double-labeling technique (31) (Fig. 8). PEGIFN- $\alpha$ /paclitaxel combination increased the percentage of apoptotic endothelial cells (yellow reactions) 5.7-fold compared with PEG-IFN- $\alpha$ alone ( $\mathrm{P}=0.002)$ (Table IA). Specifically, the percentage of apoptotic endothelial cells (\% TUNEL+) was more than 15-fold of apoptotic tumor cells in mice treated with PEG-IFN- $\alpha$ /paclitaxel combination (Table IB).

\section{Discussion}

We report that two times per week injections of $10 \mathrm{KU}$ of PEGIFN- $\alpha$ in combination with paclitaxel for 4 weeks into nude mice bearing orthotopically human glioblastoma cells inhibited angiogenesis and tumor growth. Altering the dose and schedule of PEG-IFN- $\alpha$ profoundly influenced the therapeutic outcome. IFN has been shown to inhibit angiogenesis by decreasing the transcription and protein production of many proangiogenic molecules, such as bFGF, VEGF and MMP-9, which are also survival factors for tumor and endothelial cells $(14,25,32)$. However, different doses of PEG-IFN- $\alpha$ altered the expression of these factors dose-dependently, showing that PEG-IFN- $\alpha$ administered at higher or lower doses was less effective $(25,32)$. This regulation is associated with induction of feedback mechanism involving a family of proteins called SOCS (suppressor of cytokine signaling) $(33,34)$. To control excessive cytokine effects, higher levels of SOCS1 negatively regulate cytokine signaling and fail to regulate their target genes

\begin{tabular}{|c|c|c|c|c|c|c|}
\hline \multirow{2}{*}{$\begin{array}{l}\text { B, } \\
\text { Treatment group }\end{array}$} & \multicolumn{3}{|c|}{ Tumor cells } & \multicolumn{3}{|c|}{ Endothelial cells } \\
\hline & DAPI & TUNEL & $\%$ TUNEL+ & DAPI & TUNEL & $\%$ TUNEL+ \\
\hline PEG-IFN- $\alpha+$ paclitaxel & $306 \pm 27^{d}$ & $7 \pm 1^{\mathrm{d}}$ & $2.3 \pm 0.2^{\mathrm{e}}$ & $39 \pm 5$ & $10 \pm 7$ & $30.2 \pm 13^{\mathrm{e}}$ \\
\hline
\end{tabular}

aTumor cells were orthotopically implanted into mouse brains and then the mice received PBS (control), $10 \mathrm{KU}$ of PEG-IFN- $\alpha, 200 \mu \mathrm{g}$ of paclitaxel, or PEG-IFN- $\alpha$ /paclitaxel combination. PEG-IFN- $\alpha$ and paclitaxel was administered two times per week for 4 weeks s.c. and i.p., respectively. ${ }^{b}$ Percentage of CD31/TUNEL+ cells in 10 random fields at magnification $x 400$. Fluorescence double labeling was performed on frozen tissue sections. ${ }^{\mathrm{C}}<0.01$ compared to the controls. ${ }^{\mathrm{d}}$ Mean $\pm \mathrm{SD}$, number of positive cells in 10 random fields at magnification $\mathrm{x} 400 .{ }^{\mathrm{e}} \mathrm{P}<0.001$. 

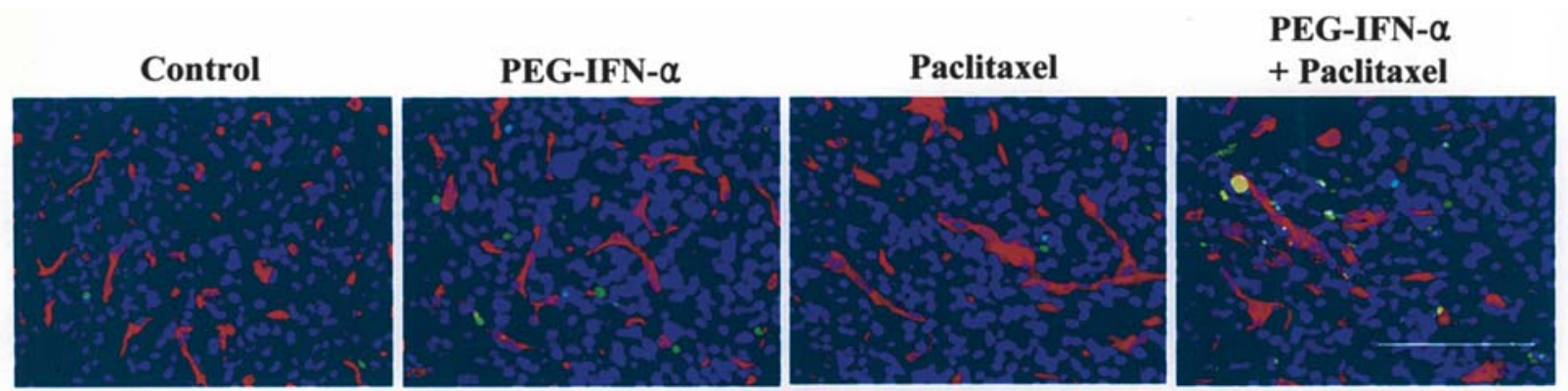

Figure 8. Immunofluorescent CD31 (endothelial cells)/TUNEL (apoptosis) double labeling. Tumor sections were stained with anti-CD31 antibodies (red), TUNEL (green), and DAPI (blue, nuclei). A representative sample is shown. Apoptotic endothelial cells are seen as yellow. Scale bar, $100 \mu \mathrm{m}$.

(35). Indeed, we found that, at doses exceeding $125 \mathrm{KU}$ PEGIFN- $\alpha$, the expression of bFGF, VEGF and MMP-9 were not reduced by PEG-IFN- $\alpha$ administration (Figs. 1 and 2). Therefore, to produce maximal therapeutic effects, IFN must be administered at an optimal biological dose. Further, to achieve the most powerful anti-tumor effect, it is important to determine the most effective schedule of PEG-IFN- $\alpha$ administration. We found chronic treatment (4 weeks) was more effective than short-term treatment ( 2 weeks) via significant decrease in cell proliferation (Fig. 3) and microvascular density (MVD) (Fig. 4).

IFN- $\alpha$ has been widely used alone or in combination with other agents to treat a variety of neoplasms, including melanoma, renal cell carcinoma, bladder cancer and ovarian carcinoma $(4,10,12,23,25,26)$. However, response rates have been modest, and the optimal dosing schedule in glioma has not been determined. We show that administration of PEGIFN- $\alpha$ at the optimal biological dose and schedule (10 KU, 4week treatment) in combination with paclitaxel significantly reduced the progressive growth of human glioblastoma cells implanted orthotopically in nude mice in a synergistic fashion (Fig. 5). The inhibition in tumor size directly correlated with inhibition of cell proliferation and tumor vascularization, and induction of apoptosis, which was revealed by immunohistochemical analysis using antibodies against PCNA and CD31, or TUNEL assay (Figs. 6 and 7).

The reduction in angiogenesis was mainly due to a significant increase in endothelial cell apoptosis (Fig. 8). Specifically, PEG-IFN- $\alpha$ /paclitaxel combination enhanced the percentage of apoptotic endothelial cells rather than the tumor cells themselves (Table I). The following points are noteworthy for combination therapy: i) A low dose of drug can effectively target tumor cells because endothelial cells in the tumor bed are easily accessible by circulation (36) and, by targeting these cells, tumor growth is slowed through regression of its vascular bed. Using lower doses, as in this study, toxicity can be minimized, and therapeutic efficacy maintained. ii) Drug resistance by the blood-brain barrier (BBB) can be avoided, as endothelial cell apoptosis induced by PEG-IFN- $\alpha$ may lead to leaky vessels and increase the tumor penetration of paclitaxel. The increased penetration of paclitaxel allowed by PEG-IFN- $\alpha$ may improve the effect of this chemotherapeutic agent, since prior studies using paclitaxel showed only a modest effect in glioblastoma patients (37). Major problems for the effectiveness of brain tumor treatments are tumor cell drug resistance, lack of drug penetration caused by the BBB, compensatory mechanisms of tumor cell survival via various survival factors, and the biological and genetic heterogeneity of tumors. Therapy based on the anti-angiogenic activities of PEG-IFN- $\alpha$ resulting in apoptosis of endothelial cells prior to the apoptosis of tumor cells may help overcome these difficulties in brain tumor treatment. Supporting the concept of the anti-angiogenic, and synergistic chemotherapy activity of PEG-IFN- $\alpha$, preliminary data from an ongoing study of temozolomide plus PEG-IFN- $\alpha$ at $0.5 \mu \mathrm{g} / \mathrm{kg} /$ week in adults with recurrent glioblastoma patients demonstrated a $79 \%$ improvement in 6-month progression-free survival over temozolomide as a single agent (Groves et al, Proc ASCO, abs. 1519: S118, 2005).

Collectively, this study demonstrates that combining the optimal biological dose and schedule of PEG-IFN- $\alpha$ with paclitaxel would synergistically impact glioblastoma cell growth. The mechanisms of the significant therapeutic effects were most likely caused by direct down-regulation of the expression of bFGF, VEGF, and, MMP-9; inhibition of cell proliferation; and an increase in apoptosis of tumor-associated endothelial cells. These results suggest that PEG-IFN- $\alpha$ / paclitaxel combination may provide a novel and effective approach to the treatment of human glioblastoma.

\section{Acknowledgements}

This study was supported by grants from the Samsung Biomedical Research Institute (C-A4-208-2; D-H Nam), from the IN-SUNG Foundation for Medical Research (D-H Nam), and from the Korea Health 21 R\&D Project, Ministry of Health \& Welfare, Republic of Korea (Project no. 0405B002-0205-0001). The authors thank the Biostatistics Unit of Samsung Biomedical Research Institute for assistance with statistical analyses and Dr Jin Hye Seo for critically reviewing the manuscript.

\section{References}

1. Avgeropoulos NG and Batchelor TT: New treatment strategies for malignant gliomas. Oncologist 4: 209-224, 1999.

2. Kaur B, Tan C, Brat DJ, Post DE and van Meir EG: Genetic and hypoxic regulation of angiogenesis in gliomas. J Neurooncol 70: 229-243, 2004.

3. Isaacs A and Lindenmann J: Virus interference. I. The interferon. Proc R Soc Lond B Biol Sci 147: 258-267, 1957.

4. Lens MB and Dawes M: Interferon alfa therapy for malignant melanoma: a systematic review of randomized controlled trials. J Clin Oncol 20: 1818-1825, 2002. 
5. Baron S and Dianzani F: The interferons: a biological system with therapeutic potential in viral infections. Antiviral Res 24 97-110, 1994

6. Gutterman JU: Cytokine therapeutics: lessons from interferon alpha. Proc Natl Acad Sci USA 91: 1198-1205, 1994.

7. Hertzog PJ, Hwang SY and Kola I: Role of interferons in the regulation of cell proliferation, differentiation, and development. Mol Reprod Dev 39: 226-232, 1994.

8. Krown SE: Interferons in malignancy: biological products or biological response modifiers? J Natl Cancer Inst 80: 306-309, 1988 .

9. Thomas H and Balkwill FR: Effects of interferons and other cytokines on tumors in animals. Pharmacol Ther 52: 307-330, 1991.

10. Russell-Jones R: Interferon-alpha therapy for melanoma. Clin Exp Dermatol 25: 1-6, 2000.

11. Singh RK, Bucana CD, Gutman M, Fan D, Wilson MR and Fidler IJ: Organ site-dependent expression of basic fibroblast growth factor in human renal cell carcinoma cells. Am J Pathol 145: 365-374, 1994.

12. Vermeulen PB, Dirix LY, Martin M, Lemmens J and van Oosterom AT: Serum basic fibroblast growth factor and vascular endothelial growth factor in metastatic renal cell carcinoma treated with interferon alfa-2b. J Natl Cancer Inst 89: 1316-1317, 1997.

13. Oliveira IC, Sciavolino PJ, Lee TH and Vilcek J: Downregulation of interleukin 8 gene expression in human fibroblasts: unique mechanism of transcriptional inhibition by interferon. Proc Natl Acad Sci USA 89: 9049-9053, 1992.

14. Gohji K, Fidler IJ, Tsan R, Radinsky R, von Eschenbach AC, Tsuruo $\mathrm{T}$ and Nakajima M: Human recombinant interferonsbeta and -gamma decrease gelatinase production and invasion by human KG-2 renal-carcinoma cells. Int J Cancer 58: 380-384, 1994.

15. Kato N, Nawa A, Tamakoshi K, Kikkawa F, Suganuma N, Okamoto T, Goto S, Tomoda Y, Hamaguchi M and Nakajima M: Suppression of gelatinase production with decreased invasiveness of choriocarcinoma cells by human recombinant interferon beta. Am J Obstet Gynecol 172: 601-606, 1995.

16. Brouty-Boye D and Zetter BR: Inhibition of cell motility by interferon. Science 208: 516-518, 1980.

17. Sidky YA and Borden EC: Inhibition of angiogenesis by interferons: effects on tumor- and lymphocyte-induced vascular responses. Cancer Res 47: 5155-5161, 1987.

18. Kerbel R and Folkman J: Clinical translation of angiogenesis inhibitors. Nat Rev Cancer 2: 727-739, 2002.

19. Maher EA, Furnari FB, Bachoo RM, Rowitch DH, Louis DN, Cavenee WK and De Pinho RA: Malignant glioma: genetics and biology of a grave matter. Genes Dev 15: 1311-1333, 2001.

20. Wesseling P, Ruiter DJ and Burger PC: Angiogenesis in brain tumors; pathobiological and clinical aspects. J Neurooncol 32: 253-265, 1997

21. Desbaillets I, Diserens AC, De Tribolet N, Hamou MF and van Meir EG: Regulation of interleukin-8 expression by reduced oxygen pressure in human glioblastoma. Oncogene 18: 1447-1456, 1999.

22. Salmaggi A, Eoli M, Frigerio S, Silvani A, Gelati M, Corsini E, Broggi $\mathrm{G}$ and Boiardi A: Intracavitary VEGF, bFGF, IL-8, IL-12 levels in primary and recurrent malignant glioma. J Neurooncol 62: 297-303, 2003.
23. Tedjarati S, Baker CH, Apte S, Huang S, Wolf JK, Killion JJ and Fidler IJ: Synergistic therapy of human ovarian carcinoma implanted orthotopically in nude mice by optimal biological dose of pegylated interferon alpha combined with paclitaxel. Clin Cancer Res 8: 2413-2422, 2002.

24. Kirkwood JM and Ernstoff MS: Interferons in the treatment of human cancer. J Clin Oncol 2: 336-352, 1984.

25. Slaton JW, Perrotte P, Inoue K, Dinney CP and Fidler IJ: Interferon-alpha-mediated down-regulation of angiogenesis-related genes and therapy of bladder cancer are dependent on optimization of biological dose and schedule. Clin Cancer Res 5: 2726-2734, 1999

26. Motzer RJ, Rakhit A, Ginsberg M, Rittweger K, Vuky J, Yu R, Fettner S and Hooftman L: Phase I trial of 40-kd branched pegylated interferon alfa-2a for patients with advanced renal cell carcinoma. J Clin Oncol 19: 1312-1319, 2001.

27. Nam DH, Park K, Park C, Im YH, Kim MH, Lee S, Hong SC, Shin HJ, Kim JH, Eoh W and McDonnell TJ: Intracranial inhibition of glioma cell growth by cyclooxygenase-2 inhibitor celecoxib. Oncol Rep 11: 263-268, 2004.

28. Lal S, Lacroix M, Tofilon P, Fuller GN, Sawaya R and Lang FF: An implantable guide-screw system for brain tumor studies in small animals. J Neurosurg 92: 326-333, 2000.

29. Kuniyasu H, Ellis LM, Evans DB, Abbruzzese JL, Fenoglio CJ, Bucana CD, Cleary KR, Tahara E and Fidler IJ: Relative expression of E-cadherin and type IV collagenase genes predicts disease outcome in patients with resectable pancreatic carcinoma. Clin Cancer Res 5: 25-33, 1999.

30. Perrotte P, Matsumoto T, Inoue K, Kuniyasu H, Eve BY, Hicklin DJ, Radinsky R and Dinney CP: Anti-epidermal growth factor receptor antibody C225 inhibits angiogenesis in human transitional cell carcinoma growing orthotopically in nude mice. Clin Cancer Res 5: 257-265, 1999.

31. Bruns CJ, Solorzano CC, Harbison MT, Ozawa S, Tsan R, Fan D, Abbruzzese J, Traxler P, Buchdunger E, Radinsky R and Fidler IJ: Blockade of the epidermal growth factor receptor signaling by a novel tyrosine kinase inhibitor leads to apoptosis of endothelial cells and therapy of human pancreatic carcinoma. Cancer Res 60: 2926-2935, 2000.

32. Singh RK, Gutman M, Bucana CD, Sanchez R, Llansa N and Fidler IJ: Interferons alpha and beta down-regulate the expression of basic fibroblast growth factor in human carcinomas. Proc Natl Acad Sci USA 92: 4562-4566, 1995.

33. Narazaki M, Fujimoto M, Matsumoto T, Morita Y, Saito H, Kajita T, Yoshizaki K, Naka T and Kishimoto T: Three distinct domains of SSI-1/SOCS-1/JAB protein are required for its suppression of interleukin 6 signaling. Proc Natl Acad Sci USA 95: 13130-13134, 1998

34. Nicholson SE and Hilton DJ: The SOCS proteins: a new family of negative regulators of signal transduction. J Leukoc Biol 63: 665-668, 1998

35. Leroith D and Nissley P: Knock your SOCS off! J Clin Invest 115: 233-236, 2005

36. Folkman J: Angiogenesis and apoptosis. Semin Cancer Biol 13: 159-167, 2003

37. Fetell MR, Grossman SA, Fisher JD, Erlanger B, Rowinsky E, Stockel J and Piantadosi S: Preirradiation paclitaxel in glioblastoma multiforme: efficacy, pharmacology, and drug interactions. New Approaches to Brain Tumor Therapy Central Nervous System Consortium. J Clin Oncol 15: 3121-3128, 1997. 